\title{
Diagnostic accuracy of DXA compared to conventional spine radiographs for the detection of vertebral fractures in children
}

\author{
E. Adiotomre ${ }^{1,2} \cdot$ L. Summers ${ }^{3}$ A. Allison ${ }^{4}$ - S. J. Walters ${ }^{4} \cdot$ M. Digby ${ }^{3} \cdot$ P. Broadley $^{2}$. \\ I. Lang ${ }^{2} \cdot$ G. Morrison ${ }^{5}$ N. Bishop ${ }^{6} \cdot$ P. Arundel ${ }^{6}$ A. C. Offiah ${ }^{2,6}$
}

Received: 15 March 2016 /Revised: 5 July 2016 / Accepted: 9 August 2016/Published online: 21 September 2016

(C) The Author(s) 2016. This article is published with open access at Springerlink.com

\begin{abstract}
Objectives In children, radiography is performed to diagnose vertebral fractures and dual energy x-ray absorptiometry (DXA) to assess bone density. In adults, DXA assesses both. We aimed to establish whether DXA can replace spine radiographs in assessment of paediatric vertebral fractures.

Methods Prospectively, lateral spine radiographs and lateral spine DXA of 250 children performed on the same day were independently scored by three radiologists using the simplified algorithm-based qualitative technique and blinded to results of the other modality. Consensus radiograph read and second read of 100 random images were performed. Diagnostic accuracy, inter/intraobserver and intermodality
\end{abstract}

A. C. Offiah

a.offiah@sheffield.ac.uk

1 Radiology Department, Sheffield Teaching Hospitals NHS Foundation Trust, Glossop Rd, Sheffield, South Yorkshire S10 2JF, UK

2 Radiology Department, Sheffield Children's Hospital NHS Foundation Trust, Western Bank, Sheffield, South Yorkshire S10 2TH, UK

3 Sheffield Medical School, University of Sheffield, Beech Hill Rd, Sheffield, South Yorkshire S10 2RX, UK

4 School of Health and Related Research, University of Sheffield, 30 Regent St, Sheffield, South Yorkshire S1 4DA, UK

5 Medical Physics, Sheffield Teaching Hospitals NHS Foundation Trust, Glossop Rd, Sheffield, South Yorkshire S10 2JF, UK

6 Academic Unit of Child Health, University of Sheffield, Western Bank, Sheffield, South Yorkshire S10 2TH, UK agreements, patient/carer experience and radiation dose were assessed.

Results Average sensitivity and specificity (95\% confidence interval) in diagnosing one or more vertebral fractures requiring treatment was $70 \%(58-82 \%)$ and $97 \%(94-100 \%)$ respectively for DXA and $74 \%(55-93 \%)$ and $96 \%$ (95$98 \%$ ) for radiographs. Fleiss' kappa for interobserver and average kappa for intraobserver reliability were 0.371 and 0.631 respectively for DXA and 0.418 and 0.621 for radiographs. Average effective dose was $41.9 \mu \mathrm{Sv}$ for DXA and $232.7 \mu \mathrm{Sv}$ for radiographs. Image quality was similar.

Conclusion Given comparable image quality and non-inferior diagnostic accuracy, lateral spine DXA should replace conventional radiographs for assessment of vertebral fractures in children.

Key Points

- Vertebral fracture diagnostic accuracy of lateral spine DXA is non-inferior to radiographs.

- The rate of unreadable vertebrae for DXA is lower than for radiographs.

- Effective dose of DXA is significantly lower than radiographs.

- Children prefer DXA to radiographs.

- Given the above, DXA should replace radiographs for paediatric vertebral fracture assessment.

Keywords Spinal fractures · Osteoporosis · Interobserver variability $\cdot$ Dual energy $x$-ray absorptiometry $\cdot$ Radiography
Abbreviations and acronyms
BMD bone mineral density
DAP dose area product
DXA dual energy x-ray absorptiometry
ED effective dose 


\section{ESD entrance surface dose}

OI osteogenesis imperfecta

sABQ simplified algorithm-based qualitative

VF vertebral fracture(s)

VFA densitometric vertebral fracture assessment

\section{Introduction}

Radiation exposure is directly associated with cancer risk [1-3]. The earlier the radiation exposure, the higher the risk of radiation-induced cancer [4, 5]. Children have a higher mitotic rate and therefore increased susceptibility to radiation and a longer lifespan to accumulate dose and manifest radiation-induced cancer $[4,6]$. Repeated spine radiographs in adolescent scoliosis [7] and fluoroscopy in tuberculosis [8] are associated with increased risk of breast cancer. There is no minimum dose threshold at which radiation does not have a cancer risk but the dose response is linear for solid cancers and linear-quadratic for leukaemia [4, 5]. The Committee on Biological Effects on Ionizing Radiation VII lifetime risk model suggests that an increase of $100 \mathrm{mSv}$ above background radiation could cause 1 cancer per 100 people [9]. The typical effective dose (ED) of one chest radiograph in a 10 -year-old child is $0.006 \mathrm{mSv}$ [5]. A study on cumulative radiation doses in children with spinal dysraphism calculated mean childhood cumulative ED of $23 \mathrm{mSv}$ with an additional cancer risk of $0.37 \%$ ( 1 in 270 ) based on a risk of $16 \%$ per Sv [10]. Therefore, the lowest dose investigation that meets clinical need should be used, particularly in patients where repeated exposures are required.

Densitometric vertebral fracture assessment (VFA) was first described by Genant in 2000 [11, 12]. There is a range of favourable VFA literature in adults [13-16], demonstrating sensitivity and specificity ranging from 62 to $97 \%$ and 94 to $99 \%$ respectively $[14,15,17-22]$. VFA is recommended as a complement to densitometry for improved clinical evaluation of asymptomatic VF in adults [23-25]. Although the importance of VF in the definition of osteoporosis in children is well established [26] and despite VFA being associated with lower radiation doses of 3-20 $\mu \mathrm{Sv}[23,27,28]$ compared to 600$3000 \mu \mathrm{Sv}$ for radiographs [23, 27, 28], there are no recommendations for VFA in children. Generally, children with suspected reduced bone mineral density (BMD) have dual energy $\mathrm{x}$-ray absorptiometry (DXA) to assess BMD and radiographs to identify vertebral fractures (VF), leading to significant lifetime cumulative radiation dose.

The aim of this study was to determine whether DXA, specifically iDXA (GE Healthcare Lunar iDXA, Buckinghamshire, UK), can replace radiographs for diagnosis of VF in children with suspected reduced BMD either with primary osteoporosis such as osteogenesis imperfecta or with secondary osteoporosis such as those treated with steroids or who have leukaemia.

\section{Methods}

The study was funded by the National Institute for Health Research "Research for Patient Benefit Programme" (Reference PB-PG-0110-21240). Local ethics committee and Research and Development approval (Reference 11/YH/ 0292) and patient/guardian assent/consent were obtained.

Two hundred and fifty patients aged 5 years to 15 years (inclusive) were recruited between November 2011 and February 2014 from two tertiary paediatric centres; 200 with suspected reduced BMD attending the metabolic bone clinic for iDXA and lateral spine radiographs and 50 attending spine clinic requiring lateral spine radiographs as part of routine care who were consented for an additional lateral iDXA. Participants were only recruited into the study once (Fig. 1).

One hundred and fifty one patients were recruited prospectively and 99 retrospectively (33 from our centre, 66 from Birmingham Children's Hospital - $\mathrm{BCH}$ ).

Assuming (1) the true VF rate is $30 \%$ and (2) $80 \%$ sensitivity/specificity for the tests, then recruiting 250 patients (75 with VF), we can estimate sensitivity/specificity of DXA ( $\pm 9 \%$ ) and radiography ( $\pm 6 \%$ ) with $95 \%$ confidence.

iDXA was performed according to published recommendations [29]. Radiographs were obtained on one of two local machines (TH3 Digital or TH Bucky Diagnost, Phillips, Guildford UK) or one of two machines at BCH (Luminus DRF, Siemens, Camberley UK, or CPI Wolverson Acroma unit, Willenhall UK) adhering to the European guidelines for spine radiographs in children [30]. Depending on patient size, single thoracolumbar or separate thoracic and lumbar exposures were taken. Radiographs were obtained in the lateral decubitus position for patients with suspected reduced BMD and in a standing lateral position for spine clinic patients. Average exposures were $73 \mathrm{kV}, 82 \mathrm{kV}$ and $103 \mathrm{kV}$ for thoracic, lumbar and thoracolumbar radiographs respectively. Detector focus distance was $100 \mathrm{~cm}$ for decubitus and $210 \mathrm{~cm}$ for standing spine radiographs.

iDXA and radiographs for each patient were acquired on the same day.

Blinded to clinical information and corresponding results of the other modality, three consultant paediatric musculoskeletal radiologists (PB, IL, ACO), each with minimum 10 years' experience, independently scored anonymised images in random order, for (1) presence of fractures and (2) image quality according to modified European criteria [30]. A hundred randomly selected pairs of images were read a second time. A final consensus read of all 250 radiographs acted as reference standard. Quantitative measurements using workstation measurement tools only took place at the reader's discretion. The 


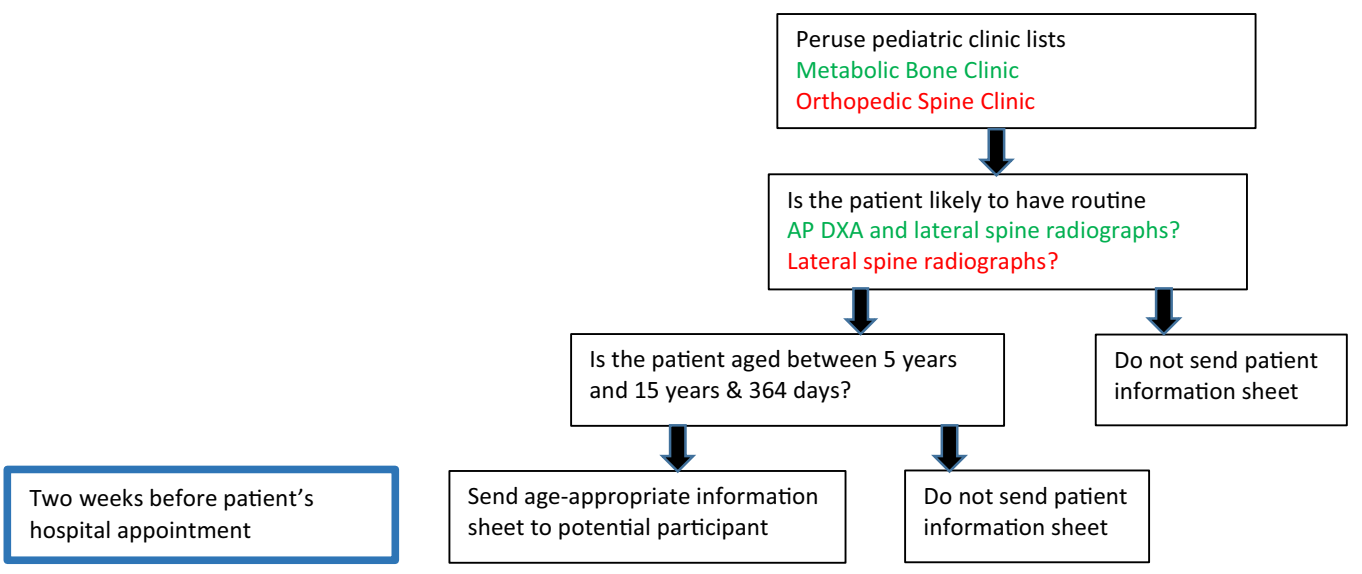

On the day of patient's hospital appointment

Is the patient having routine

AP \& lateral spine radiographs?

Lateral spine radiographs?

Does the patient meet study inclusion criteria?

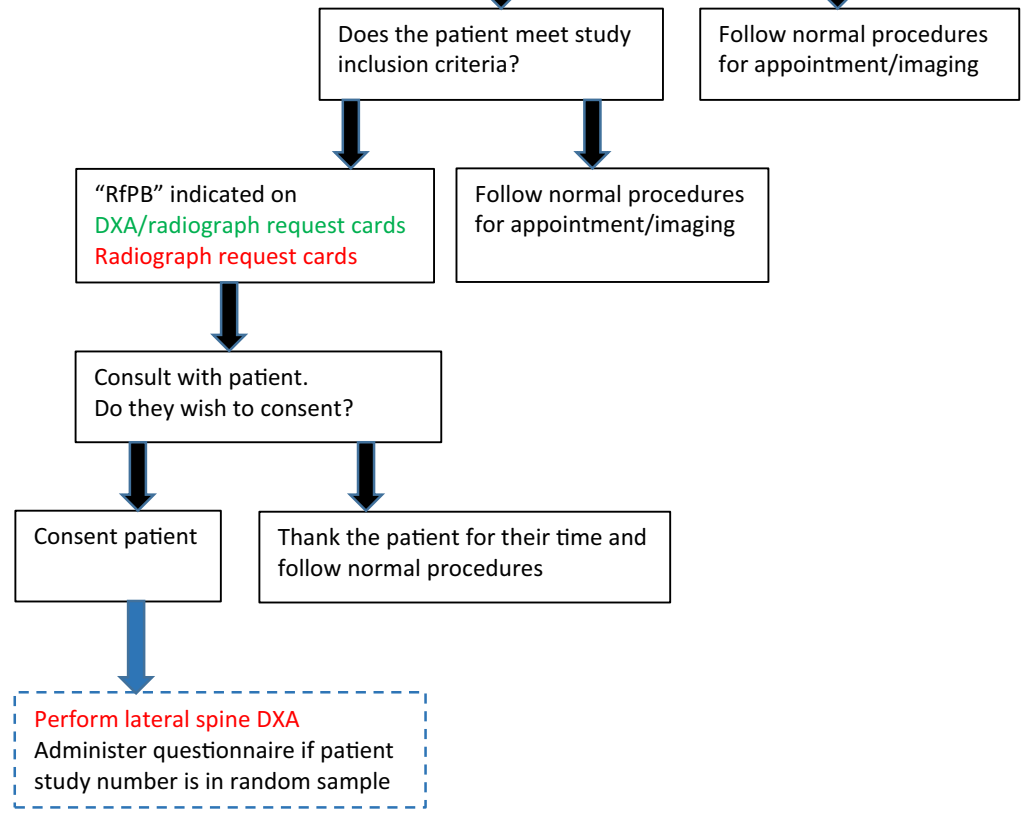

Green text $=$ Metabolic Bone Clinic patients. Red text $=$ Spine Clinic patients. Black text $=$ All patients.

Fig. 1 Flow chart demonstrating patient recruitment process from metabolic bone and spine clinics

vertebrae were graded for fracture from 0 to 4 according to the simplified algorithm-based qualitative score (which is a modification of the Ferrar et al. algorithm-based qualitative vertebral fracture assessment technique [18]):
0) Normal

1) Fracture with $24 \%$ or less height loss

2) Fracture with $25 \%$ or more height loss

3) Non-osteoporotic deformity 
4) Uncertain or unable to determine due to quality [31].

Because only lateral images were assessed and for consistency of vertebral level assignment between observers, the first vertebral body not associated with ribs was always designated L1 and the lowermost vertebral body associated with ribs was designated T12. If T12 and L1 could not be identified (e.g. excessive coning), all vertebrae were scored unreadable.

A questionnaire (non-validated) was randomly administered to assess patient and carer experience.

Radiation dose was calculated using dose area product (DAP) for radiographs and recorded exposure factors, scan areas and entrance surface dose (ESD) for iDXA. Average DAP was calculated and used to estimate average ED using PCXMC 2.0 software for different age groups to estimate the relative risk of each modality. Average lifetime additional cancer risk was calculated using the Health Protection Agency's proposed total lifetime cancer risk per unit of ED (percentage per Sievert) as a function of age at exposure and sex.

Statistical analysis was performed using $\mathrm{R}$ Software Version 3.0.2 for PC. Using the consensus radiographic read as reference standard, we calculated and compared the prevalence of VF (percentage patients identified with one or more VF and percentage VF from the total of 3250 vertebrae) and iDXA/radiograph sensitivity/specificity. Previously surveyed clinicians initiate treatment once there is vertebral body height loss of $25 \%$ or more plus pain [31]; therefore, patients were classified into two groups: no treatment (no VF or VF with a height loss of less than $25 \%, \mathrm{VF}_{0} / \mathrm{VF}_{-25}$ ) and treatment (one or more VF with a height loss of equal to/more than $25 \%$, $\mathrm{VF}_{+25}$ ) groups. Unreadable vertebrae within these groups were included in statistical analyses. Kappa statistics were used to assess inter/intraobserver and intermodality agreement. Fleiss' kappa was used to assess agreement between all three observers simultaneously. Paired samples Student's $t$ test was used to compare radiation doses of the two modalities.

\section{Results}

\section{Demographics}

Mean patient age was 11.5 years; 104 (42\%) were male; 142 (57\%) self-classified as Caucasian, 109 (44\%) had osteogenesis imperfecta (OI). The other 90 children with suspected reduction in BMD had various diagnoses including inflammatory bowel disease, rheumatological conditions, coeliac disease, cystic fibrosis and unexplained fractures. 37(74\%) of the 50 spine clinic patients attended for scoliosis.

\section{Fracture characteristics/image analysis}

\section{Vertebral level}

Of the 3250 vertebrae assessed, 364 (11\%) were fractured, with $\mathrm{T} 7$ being the most frequently fractured level (47/250, $19 \%)$. Table 1 summarises fracture characteristics for the consensus and individual iDXA/radiograph reads.

Figure 2 compares (a) iDXA to (b) radiography in a patient with OI; vertebrae T5 to T11 were independently identified by all observers on both iDXA and radiography as fractures with a height loss equal to or more than $25 \%$.

Figure 3 compares (a) iDXA to $(b, c)$ radiography in a patient with severe OI.

Image quality A total of 460 (14\%) vertebrae were unreadable. Reasons included excessive coning either obscuring T12/L1 so that reliable vertebral levels could not be assigned or obscuring other vertebrae, poor image quality and patient positioning.

Of the 3250 vertebrae, the number unreadable on iDXA was $262(8 \%), 337(10 \%)$ and $232(7 \%)$ for radiologists 1 , 2 and 3 respectively. The number for radiographs was 300 $(9 \%), 411(13 \%)$ and $504(16 \%)$. The percentage of unreadable images varied by vertebral level, image modality and observer. Overall, the level with the highest number of unreadable vertebrae was T4 $(27.6 \%)$; this was true for all three observers and both modalities. Similarly, overall, the levels with the lowest number of unreadable vertebrae were L1 to L3 $(4.8 \%)$ and this was generally true for all three observers and both modalities. Results for each level, observer and modality are summarised in Table 2.

Twenty-four patients had spinal rods in situ for scoliosis correction. There were on average less unreadable vertebrae for patients with spinal rods from iDXA (4, 7 and 4 for radiologists 1, 2 and 3 respectively) compared to radiographs $(6,8$ and 7). The difference was statistically significant for radiologists 1 and 3 ( $p$ values 0.041 and 0.005 respectively).

Figure 4 compares (a) iDXA to (b) radiography in a postoperative scoliosis patient with spinal fixation; image quality with spinal rods in situ was degraded on radiographs from T4 to T6 but maintained on iDXA.

\section{Patient level}

Overall, 90 (36\%) patients had one or more VF (vertebral height loss $10 \%$ or more). A total of 181 (72\%) patients had valid consensus radiograph data allowing definitive categorisation into no treatment $\left(\mathrm{VF}_{0} / \mathrm{VF}_{-25}\right)$ or treatment $\left(\mathrm{VF}_{+25}\right)$ groups. The remaining $69(28 \%)$ had a combination of unreadable vertebrae and $\mathrm{VF}_{0}$ and were excluded from diagnostic accuracy calculations as a result of the inability to 
Table 1 Summary of fracture characteristics for the 250 individual and consensus reads

\begin{tabular}{|c|c|c|c|c|c|c|c|c|c|c|c|c|c|c|}
\hline & \multicolumn{2}{|c|}{$\begin{array}{l}\text { Reference } \\
\text { Standard } \\
\text { Consensus } \\
\text { Radiograph }\end{array}$} & \multicolumn{2}{|c|}{$\begin{array}{l}\text { Observer } 1 \\
\text { Radiograph }\end{array}$} & \multicolumn{2}{|c|}{$\begin{array}{l}\text { Observer } 2 \\
\text { Radiograph }\end{array}$} & \multicolumn{2}{|c|}{$\begin{array}{l}\text { Observer } 3 \\
\text { Radiograph }\end{array}$} & \multicolumn{2}{|l|}{$\begin{array}{l}\text { Observer } 1 \\
\text { DXA }\end{array}$} & \multicolumn{2}{|c|}{$\begin{array}{l}\text { Observer } \\
2 \text { DXA }\end{array}$} & \multicolumn{2}{|c|}{$\begin{array}{l}\text { Observer } \\
3 \text { DXA }\end{array}$} \\
\hline & No. & $\%$ & No. & $\%$ & No. & $\%$ & No. & $\% \mathrm{~S}$ & No. & $\%$ & No. & $\%$ & No. & $\%$ \\
\hline Total number of fractures & 364 & 11 & 283 & 9 & 406 & 12 & 734 & 23 & 220 & 7 & 264 & 8 & 880 & 27 \\
\hline Most fractured level & $\mathrm{T} 7(47)$ & (19) & $\mathrm{T} 7(30)$ & (11) & $\mathrm{L} 2(46)$ & (11) & T6(76) & (10) & $\mathrm{T} 7, \mathrm{~L} 3(24)$ & (11) & $\mathrm{T} 7(31)$ & (12) & $\mathrm{T} 7(93)$ & (11) \\
\hline $\begin{array}{l}\text { Number of fractures involving both } \\
\text { endplates }\end{array}$ & 163 & 45 & $165^{\mathrm{a}}$ & 58 & 351 & 86 & $231^{\mathrm{b}}$ & 31 & 101 & 46 & 197 & 75 & 188 & 21 \\
\hline Number of fractures involving one endplate & 201 & 55 & $116^{\mathrm{a}}$ & 41 & 55 & 14 & $502^{\mathrm{b}}$ & 68 & 119 & 54 & 67 & 25 & 692 & 79 \\
\hline Number of fractures with height loss $<25 \%$ & 294 & 81 & 208 & 73 & 333 & 82 & 663 & 90 & 170 & 77 & 233 & 88 & 792 & 90 \\
\hline Number of patients with $\geq 1$ fracture & 90 & 36 & 78 & 31 & 95 & 38 & 159 & 64 & 71 & 28 & 82 & 33 & 176 & 70 \\
\hline $\begin{array}{l}\text { Number of patients with } \geq 1 \text { fracture and } \\
\text { height loss }<25 \%\end{array}$ & 87 & 35 & 73 & 29 & 92 & 37 & 156 & 62 & 66 & 26 & 80 & 32 & 171 & 68 \\
\hline $\begin{array}{l}\text { Number of patients with } \geq 1 \text { fracture and } \\
\text { height loss } \geq 25 \%\end{array}$ & 27 & 11 & 32 & 13 & 19 & 8 & 24 & 10 & 23 & 9 & 16 & 6 & 34 & 14 \\
\hline $\begin{array}{l}\text { Number of patients with } \geq 1 \text { fracture and } \\
\text { both endplates affected }\end{array}$ & 56 & 22 & 51 & 20 & 82 & 33 & 82 & 33 & 43 & 17 & 64 & 26 & 71 & 28 \\
\hline $\begin{array}{l}\text { Number of patients with } \geq 1 \text { fracture and } \\
\text { one end plate affected }\end{array}$ & 80 & 32 & 58 & 23 & 35 & 14 & 146 & 58 & 58 & 23 & 39 & 16 & 171 & 68 \\
\hline Number of unreadables & 460 & 14 & 300 & 9 & 411 & 13 & 504 & 16 & 262 & 8 & 337 & 10 & 232 & 7 \\
\hline
\end{tabular}

${ }^{\mathrm{a}}$ two fractures were coded as having normal end plates; ${ }^{\mathrm{b}}$ one fracture had a missing (NA) endplate code

give a definitive diagnosis (some or all of the unreadable vertebrae may have had significant loss of height).

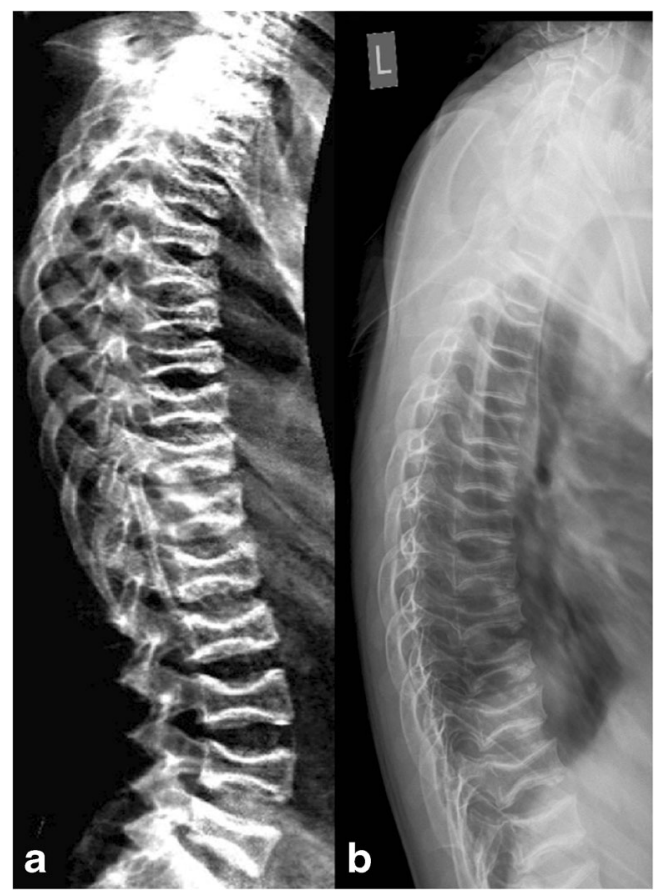

Fig. 2 Lateral iDXA (a) and thoracic spine radiograph* (b) of patient 185, an 11-year-old female with osteogenesis imperfecta. Vertebrae T5 to T11 were independently identified by all observers on both iDXA and radiographic images as $2 \mathrm{c}$ fractures which translates to a height loss of more than or equal to $25 \%$ (2), affecting both endplates (c). *The lumbar spine was included in the original radiographic examination, but for the illustrative purposes of this article, it has been omitted
Table 3 summarises diagnostic accuracy. On a patient level, for the diagnosis of any grade VF, iDXA had average sensitivity and specificity across the three radiologists of $78 \%$ (95\% confidence interval (CI) 57-99\%) and $72 \%$ (95\% CI 46-99\%) respectively and radiographs $84 \%$ (95\% CI $70-99 \%$ ) and $72 \%$ (95\% CI 47-97\%). For the diagnosis

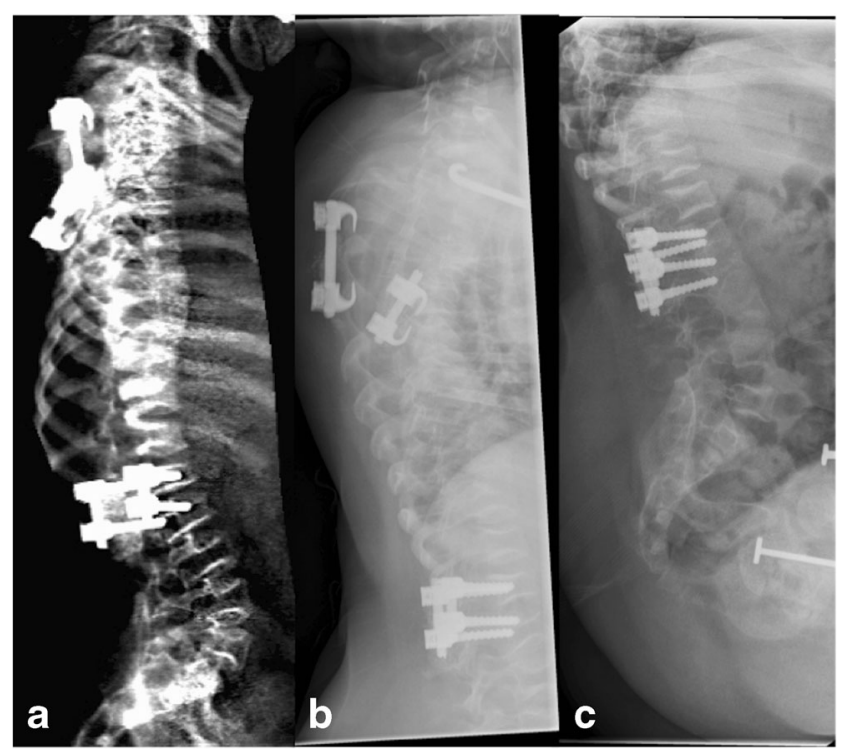

Fig. 3 Lateral iDXA (a), thoracic spine radiograph (b) and lumbar spine radiograph (c) of patient 131, a 9-year-old female with osteogenesis imperfecta. The patient had severe multilevel fractures secondary to severe disease with resultant kyphoscoliosis degrading image quality on both iDXA and radiographs. On the consensus radiographic read T4 to $\mathrm{T} 10$ were graded as unreadable because of poor image quality 
Table 2 Percentage of unreadable vertebral bodies for each vertebral level, image modality and observer

\begin{tabular}{|c|c|c|c|c|c|c|c|c|}
\hline Vertebra & $\begin{array}{l}\text { Consensus } \\
\text { X-ray } \\
\% \text { unreadable }\end{array}$ & $\begin{array}{l}\text { Observer } 1 \\
\text { X-Ray } \\
\% \text { unreadable }\end{array}$ & $\begin{array}{l}\text { Observer } 1 \\
\text { DXA } \\
\% \text { unreadable }\end{array}$ & $\begin{array}{l}\text { Observer } 2 \\
\text { X-Ray } \\
\% \text { unreadable }\end{array}$ & $\begin{array}{l}\text { Observer } 2 \\
\text { DXA } \\
\% \text { unreadable }\end{array}$ & $\begin{array}{l}\text { Observer } 3 \\
\text { X-Ray } \\
\% \text { unreadable }\end{array}$ & $\begin{array}{l}\text { Observer } 3 \\
\text { DXA } \\
\% \text { unreadable }\end{array}$ & No. of cases \\
\hline $\mathrm{T} 4$ & 27.6 & 20.8 & 16.4 & 20.4 & 19.6 & 30.4 & 16.8 & 250 \\
\hline $\mathrm{T} 5$ & 24.8 & 18.4 & 13.2 & 19.2 & 16.4 & 28.8 & 10.8 & 250 \\
\hline $\mathrm{T} 6$ & 22.4 & 14.8 & 10.4 & 18.8 & 14.0 & 27.2 & 7.2 & 250 \\
\hline $\mathrm{T} 7$ & 21.2 & 12.8 & 8.4 & 17.6 & 12.0 & 25.6 & 7.2 & 250 \\
\hline $\mathrm{T} 8$ & 18.8 & 10.0 & 8.0 & 15.2 & 9.6 & 19.6 & 6.4 & 250 \\
\hline T9 & 14.8 & 9.2 & 6.8 & 14.0 & 10.4 & 16.4 & 6.0 & 250 \\
\hline $\mathrm{T} 10$ & 14.8 & 8.4 & 6.4 & 13.2 & 10.0 & 14.4 & 7.6 & 250 \\
\hline $\mathrm{T} 11$ & 11.2 & 8.0 & 7.2 & 12.0 & 10.0 & 12.0 & 6.4 & 250 \\
\hline $\mathrm{T} 12$ & 8.4 & 6.0 & 6.8 & 10.0 & 8.4 & 7.2 & 5.6 & 250 \\
\hline L1 & 4.8 & 3.2 & 5.6 & 6.4 & 6.0 & 5.6 & 4.4 & 250 \\
\hline L2 & 4.8 & 2.8 & 5.2 & 6.0 & 6.0 & 4.0 & 4.4 & 250 \\
\hline L3 & 4.8 & 2.8 & 5.2 & 5.6 & 6.4 & 4.4 & 4.8 & 250 \\
\hline L4 & 5.6 & 2.8 & 5.2 & 6.0 & 6.0 & 6.0 & 5.2 & 250 \\
\hline
\end{tabular}

of $\mathrm{VF}_{+25}$, iDXA had average sensitivity and specificity across the three radiologists of $70 \%$ (95\% CI 58-82\%) and $97 \%$ (95\% CI 94-100\%) respectively and radiographs $74 \%(95 \%$ CI 55-93\%) and $96 \%$ (95\% CI 95-98\%).

Table 4 summarises the inter- and intraobserver agreement for the three observers for DXA and radiographs.

Table 5 summarises intermodality agreement between the three observers for iDXA versus radiographs, iDXA versus

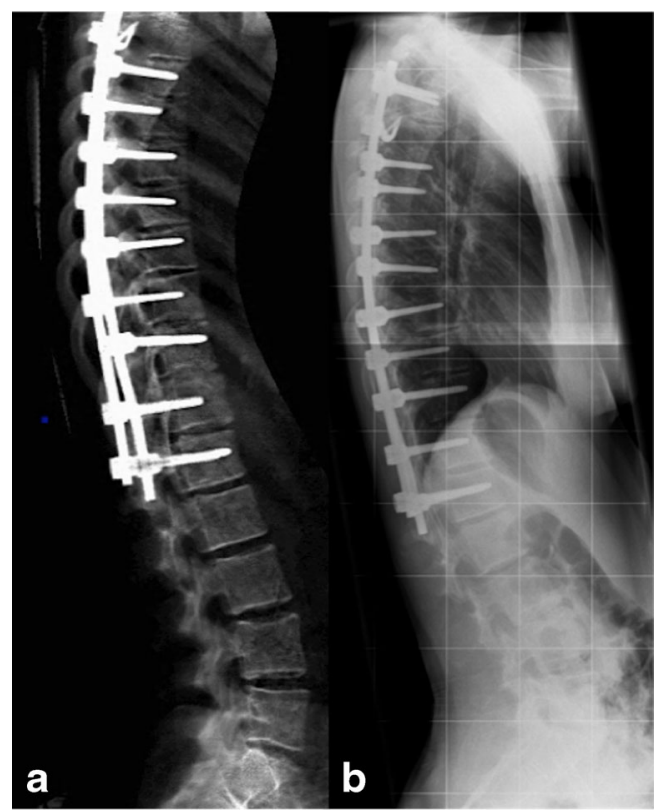

Fig. 4 Lateral iDXA (a) and thoracic spine radiograph (b) of patient 80, a 14 -year-old female with adolescent idiopathic scoliosis and previous spinal fixation. All observers independently scored vertebrae T4 to T6 as not fractured on iDXA. All observers were independently unable to score T4 to $\mathrm{T} 6$ on radiography because of poor image quality consensus/reference standard radiograph and radiograph versus consensus/reference standard radiograph.

\section{Radiation dose}

A total of 144 patients had valid radiation dose data; $95(66 \%)$ were male, mean age was 11.8 years ( $5-15$ years) and mean weight was $41.1 \mathrm{~kg}(14.3-87.5 \mathrm{~kg})$. The mean DAP for iDXA was $18.0 \mu \mathrm{Gy} / \mathrm{m}^{2}$ (SD 3.4) compared to $64.4 \mu \mathrm{Gy} / \mathrm{m}^{2}$ (SD 76.7) for radiographs, a difference of $46.4 \mu \mathrm{Gy} / \mathrm{m}^{2}$ (95 \% CI 33.7-59.1), $p<0.001$. Average age-adjusted ED for iDXA was $41.9 \mu \mathrm{Sv}$ compared to $232.7 \mu \mathrm{Sv}$ for radiographs.

The average lifetime additional cancer risk per lateral iDXA was calculated to be $0.001 \%$ and $0.000 \%$ for patients aged 5-10 and 10-15 years respectively for both sexes. Per lateral spine radiograph the additional lifetime cancer risk was $0.003 \%$ for boys and $0.002 \%$ for girls aged $5-15$ years.

\section{Patient experience}

Eighty-five sets ( $85 \%)$ of patient/carer questionnaires were returned. Of these, 77 (91\%) were completed by patient and carer, five $(6 \%)$ by the carer only and three $(3 \%)$ by the child only. Of the 82 carers that completed a questionnaire, 11 (13\%) thought their child had difficulty staying still whilst the radiographs were obtained compared to $8(10 \%)$ for iDXA $(p=0.549)$. Two $(2 \%)$ carers thought their children (aged 10.3 and 15.8 years) found the noise of the iDXA upsetting or frightening.

Eighty children (32 aged 5-11 years and 48 aged 1215 years) completed questionnaires. Thirty-nine (49\%) preferred iDXA while $27 \%$ (34\%) had no preference. Sixty-nine 


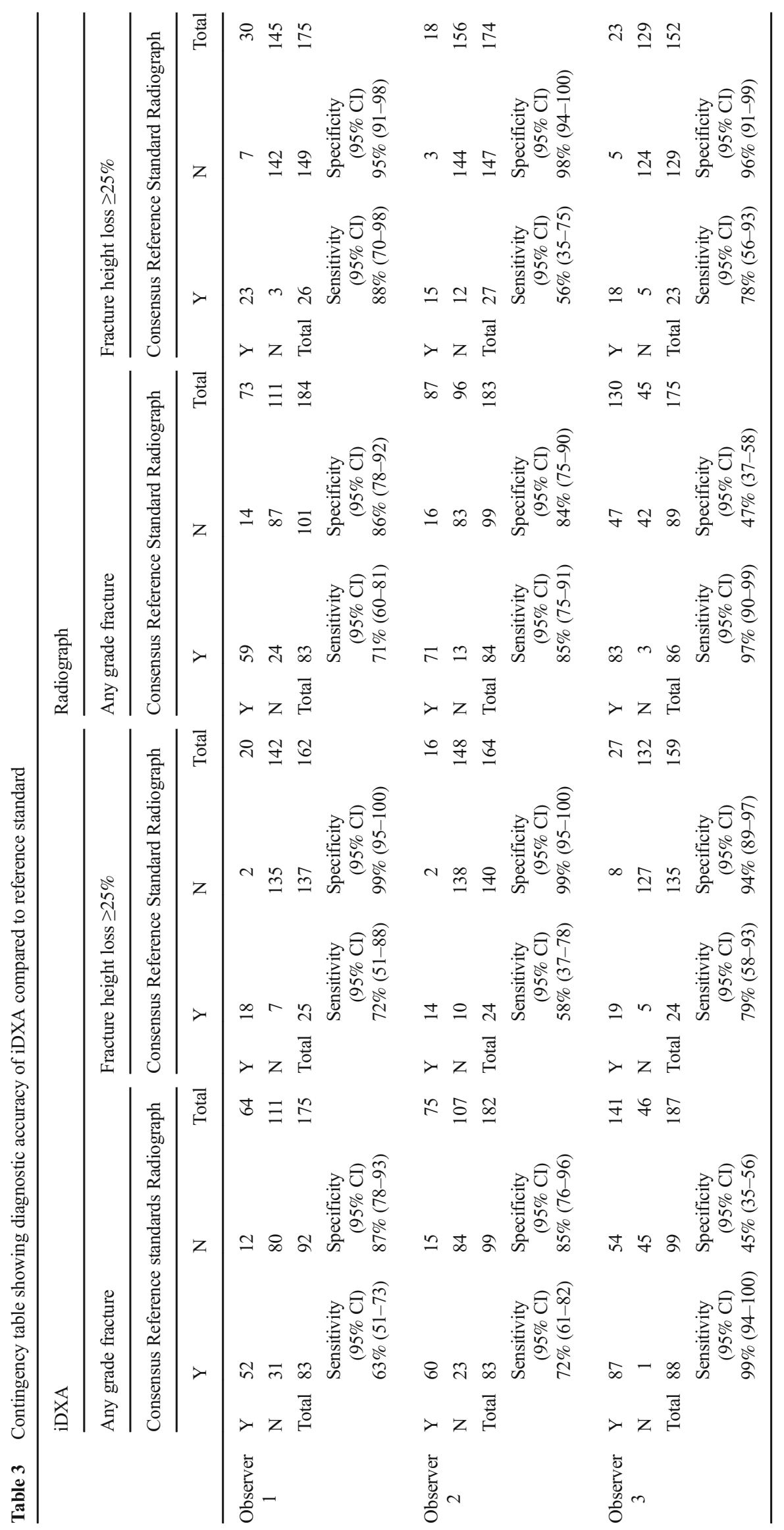


Table 4 Summary of observer agreements

Inter-observer agreement $(n=250)$

\begin{tabular}{|c|c|c|c|c|c|c|c|c|c|c|}
\hline & & & \multicolumn{4}{|l|}{ DXA } & \multicolumn{4}{|c|}{ Radiographs } \\
\hline & & & \multicolumn{3}{|c|}{ Kappa } & \multirow{2}{*}{$\begin{array}{l}\% \text { agreement } \\
\text { Mean }\end{array}$} & \multicolumn{3}{|l|}{ Kappa } & \multirow{2}{*}{$\begin{array}{l}\% \text { agreement } \\
\text { Mean }\end{array}$} \\
\hline & & & Mean & Min & Max & & Mean & Min & Max & \\
\hline \multirow[t]{7}{*}{ Fracture detection } & Observers & 1 vs 2 & 0.50 & 0.35 & 0.60 & 91 & 0.46 & 0.32 & 0.59 & 77 \\
\hline & & 1 vs 3 & 0.32 & 0.19 & 0.42 & 73 & 0.43 & 0.26 & 0.62 & 74 \\
\hline & & 2 vs 3 & 0.37 & 0.30 & 0.47 & 74 & 0.39 & 0.26 & 0.60 & 72 \\
\hline & \multirow{2}{*}{\multicolumn{2}{|c|}{$\begin{array}{l}\text { Simultaneous agreement across } 3 \\
\text { observers }\end{array}$}} & \multicolumn{3}{|c|}{ Fleiss’ Kappa } & $\%$ agreement & \multicolumn{3}{|c|}{ Fleiss’ Kappa } & $\%$ agreement \\
\hline & & & \multicolumn{3}{|l|}{0.37} & 66 & \multicolumn{3}{|l|}{0.42} & 64 \\
\hline & & & \multicolumn{3}{|l|}{ Kappa } & $\%$ agreement & \multicolumn{3}{|l|}{ Kappa } & $\%$ agreement \\
\hline & & & Mean & Min & Max & Mean & Mean & Min & Max & Mean \\
\hline \multirow[t]{5}{*}{ ABQ grading (1-4) } & Observers & 1 vs 2 & 0.47 & 0.35 & 0.56 & 84 & 0.49 & 0.39 & 0.62 & 82 \\
\hline & & 1 vs 3 & 0.30 & 0.19 & 0.40 & 70 & 0.34 & 0.27 & 0.41 & 70 \\
\hline & & 2 vs 3 & 0.35 & 0.30 & 0.43 & 72 & 0.40 & 0.32 & 0.46 & 71 \\
\hline & Simultaneo & nent across 3 & \multicolumn{3}{|c|}{ Fleiss’ Kappa } & $\%$ agreement & \multicolumn{3}{|c|}{ Fleiss' Kappa } & $\%$ agreement \\
\hline & observers & & 0.351 & & & 64 & 0.400 & & & 62 \\
\hline \multirow[t]{7}{*}{ Endplate assessment* } & & & \multicolumn{3}{|c|}{ Kappa } & $\%$ agreement & \multicolumn{3}{|l|}{ Kappa } & $\%$ agreement \\
\hline & & & Mean & Min & Max & Mean & Mean & Min & Max & Mean \\
\hline & Observers & 1 vs 2 & 0.44 & 0.33 & 0.56 & 83 & 0.49 & 0.41 & 0.62 & 81 \\
\hline & & 1 vs 3 & 0.29 & 0.16 & 0.38 & 69 & 0.33 & 0.25 & 0.62 & 69 \\
\hline & & 2 vs 3 & 0.33 & 0.25 & 0.41 & 70 & 0.38 & 0.31 & 0.44 & 69 \\
\hline & Simultaneo & nent across 3 & Fleiss' & Kappa & & $\%$ agreement & Fleiss' & Kappa & & $\%$ agreement \\
\hline & Observers & & 0.33 & & & 63 & 0.38 & & & 62 \\
\hline \multicolumn{11}{|c|}{ Intra-observer agreement $(n=100)$} \\
\hline & & & \multicolumn{4}{|l|}{ DXA } & Radiog & aphs & & \\
\hline & & & Kappa & & & $\%$ agreement & Kappa & & & $\%$ agreement \\
\hline & & & Mean & Min & Max & Mean & Mean & Min & Max & Mean \\
\hline Fracture detection & Observers & 1 & 0.61 & 0.53 & 0.71 & 89 & 0.69 & 0.59 & 0.84 & 89 \\
\hline & & 2 & 0.69 & 0.58 & 0.78 & 89 & 0.68 & 0.57 & 0.80 & 84 \\
\hline & & 3 & 0.59 & 0.49 & 0.69 & 79 & 0.49 & 0.33 & 0.66 & 73 \\
\hline & & All & 0.63 & 0.49 & 0.78 & 86 & 0.62 & 0.33 & 0.84 & 82 \\
\hline & & & Kappa & & & $\%$ agreement & Kappa & & & $\%$ agreement \\
\hline & & & Mean & Min & Max & Mean & Mean & Min & Max & Mean \\
\hline ABQ grading (1-4) & Observers & 1 & 0.58 & 0.43 & 0.67 & 87 & 0.64 & 0.51 & 0.70 & 86 \\
\hline & & 2 & 0.67 & 0.58 & 0.77 & 88 & 0.68 & 0.58 & 0.79 & 84 \\
\hline & & 3 & 0.56 & 0.47 & 0.68 & 76 & 0.48 & 0.32 & 0.65 & 72 \\
\hline & & All & 0.60 & 0.43 & 0.77 & 84 & 0.60 & 0.32 & 0.79 & 81 \\
\hline & & & Kappa & & & $\%$ agreement & Kappa & & & $\%$ agreement \\
\hline & & & Mean & Min & Max & Mean & Mean & Min & Max & Mean \\
\hline Endplate assessment* & Observers & 1 & 0.58 & 0.45 & 0.68 & 88 & 0.64 & 0.54 & 0.71 & 86 \\
\hline & & 2 & 0.67 & 0.58 & 0.80 & 88 & 0.65 & 0.55 & 0.77 & 83 \\
\hline & & 3 & 0.54 & 0.47 & 0.62 & 75 & 0.46 & 0.32 & 0.63 & 70 \\
\hline & & All & 0.60 & 0.45 & 0.80 & 83 & 0.58 & 0.32 & 0.77 & 80 \\
\hline
\end{tabular}

*Missing values recorded as not applicable

(86\%) did not find moving about the hospital for the different tests unacceptable.

There were no adverse effects of either iDXA or radiographs.

\section{Discussion}

This is the largest study to date assessing whether VFA can replace spine radiographs in children. Overall we found iDXA 
Table 5 Summary of intermodality agreements

iDXA and radiographs $(n=250)$

Fracture detection

ABQ grading (1-4)

Observers

iDXA and consensus radiographs $(n=250)$

Fracture detection

Observers

ABQ grading (1-4)

Observers

Endplate assessment

Observers

Radiographs and consensus radiographs $(n=250)$

Fracture detection

Observers

ABQ grading (1-4)

Endplate assessment

Observers
Kappa

Mean

0.41

0.45

0.39

0.42

Kappa

Mean

0.37

0.43

0.38

0.39

Kappa

Mean

0.36

0.43

0.33

0.37

Kappa

Mean

0.32

0.39

0.34

0.35

Kappa

Mean

0.30

0.38

0.33

0.33

Kappa

Mean

0.28

0.36

0.31

0.32

Kappa

Mean

0.55

0.55

0.46

0.52

Kappa

Mean

0.53

0.54

0.46

0.51

Kappa

Mean

0.51

0.50

0.43

0.48

Min
0.32
0.38
0.29
0.29

Min
0.31
0.35
0.29
0.29

Min
0.29
0.37
0.26
0.26

0.26

Min

0.21

0.33

0.23

0.21

Min

0.21

0.30

0.24

0.21

Min

0.18

0.29

0.23

0.18

Min

0.39

0.45

0.38

0.38

Min

0.40

0.46

0.37

0.37

Min

0.40

0.39

0.37

0.37

$\begin{array}{ll} & \text { \% agreement } \\ \text { Max } & \text { Mean } \\ 0.50 & 83 \\ 0.57 & 80 \\ 0.54 & 68 \\ 0.66 & 77 \\ & \% \text { agreement } \\ \text { Max } & \text { Mean } \\ 0.46 & 81 \\ 0.55 & 79 \\ 0.50 & 67 \\ 0.55 & 75 \\ & \% \text { agreement } \\ \text { Max } & \text { Mean } \\ 0.46 & 80 \\ 0.50 & 79 \\ 0.43 & 64 \\ 0.50 & 74\end{array}$

$\%$ agreement Mean

76

78

69

74

$\%$ agreement

Mean

74

77

68

73

$\%$ agreement

Mean

74

76

67

72

$\%$ agreement Mean

84

82

75

81

$\%$ agreement

Mean

82

81

74

79

$\%$ agreement

Mean

82

79

72

78 had similar sensitivity and specificity to radiography and good intraobserver agreement, on average higher than the intraobserver agreement of radiography. A similar study of VFA in children concluded that its utility was limited by compromised visibility and poor diagnostic accuracy [27]. However, those results were based on older DXA technology
(Hologic Densitometer), a relatively small sample size ( $n=$ 65 ) and acquisition of DXA and radiographic images not on the same day but within 6 months of each other. A more recent comparative study using newer DXA technology (Hologic Discovery A Densitometer) reported sensitivity (96\%) and specificity $(100 \%)$ on a patient level (some vertebrae were 
excluded from analysis because of poor visibility) [32]. Another recent study of VFA in 165 children and adolescents compared 20 of the subjects' VFA with lateral spine radiographs (obtained within 2 months of each other), reporting sensitivity of $83 \%$ and specificity of $100 \%$ for VFA [33]. This study did not assess T4 or T5 and again excluded unreadable vertebrae from statistical analyses [33]. Diagnostic accuracy of both studies $[32,33]$ was higher than ours for both DXA and radiographs; inclusion of poorly visualised vertebrae in our statistical analyses may be seen either as a weakness or strength. Whilst diagnostic accuracy will have been improved had we excluded all poor quality images, the data as presented demonstrates the worst-case scenario.

Our results indicate that iDXA had a (statistically insignificant) lower unreadable rate than radiographs (up to $16 \%$ for both). These rates are similar to previous studies performed on adult (DXA and radiographs) [13, 14] and paediatric (radiographs) [34] populations. However iDXA had a (statistically significant) better image quality than radiographs when spinal rods were in situ.

DAP was chosen to estimate radiation dose because accurate ESD measurements using thermoluminescent dosimeters are challenging at low doses and more labour intensive. The radiographic systems had DAP meters installed and the iDXA system recorded scan area, offering simple methods for estimating doses in a large number of patients by only requiring the periodic measurement of ESD to ensure stability. Commonly published DXA doses relate to post-menopausal women over the age of 60 and reference dose data from 2006 [2]; the lifetime risk of fatal cancer in children is approximately four to five times [5] higher than this adult group. Published differences in radiation dose for radiographs and VFA (200:1) are higher than the differences shown by our study (5.5:1) [23, 27, 28]; however, published data commonly relates to standard DXA spine scans (ca. $10 \mathrm{~cm} \times 20 \mathrm{~cm}$ ) with a scan area of ca. $200 \mathrm{~cm}^{2}$, whereas the scans performed in this study had an average area of ca. $700 \mathrm{~cm}^{2}$, replicating conventional film coverage. This accounts for an estimated 3.5-fold increase in estimated ED. Our average ESD measurement of $235 \mu \mathrm{Gy}^{2}$ is similar to the published values of up to $352 \mu \mathrm{Gy}^{2}$ for a different manufacturer's scanner (Hologic QDR 4500-A) [2]. The remainder of the difference is likely due to newer digital radiographic technology with significantly lower doses compared to previous non-digital technologies. Even though dose reduction was lower than expected (demonstrating the benefit of optimised exposures delivered by dedicated paediatric radiology departments), an average annual ED reduction of $232.7 \mu \mathrm{Sv}$ per patient amounts to a considerable childhood/ lifetime cumulative dose reduction, particularly given the comparable diagnostic accuracy and patient/carer acceptability of VFA. Based on average dose calculations from our cohort of patients, for a female, estimated cumulative ED of at least $2097 \mu \mathrm{Sv}$ from an annual spine radiograph between the ages of 5 and 15 years would give an additional lifetime cancer risk of $0.022 \%$ ( 1 in 4545). For a male, estimated cumulative ED would be $2930 \mu \mathrm{Sv}$ with an additional lifetime cancer risk of at least $0.033 \%$ ( 1 in 3030). Although the overall risk per patient is low, total numbers of patients are relatively high and it is an avoidable risk without compromising diagnostic information.

If conventional radiography is required as a baseline to assess spinal deformity, such as scoliosis or kyphosis in this select group of patients with suspected reduction in BMD, then the use of EOS ${ }^{\circledR}$ for full standing radiographs of the spine is an alternative method of reducing cumulative radiation dose [35]. The limiting factor for the use of this alternative low dose technique is its availability. EOS systems are more expensive than conventional radiographic equipment and estimates of patient throughput at national level suggest that EOS is not cost-effective [36]. Therefore, the National Institute for Health and Care Excellence (NICE) does not currently recommend the routine use of EOS in the National Health Service (NHS) [37]. Although EOS produces images of equal or better quality than radiographs at doses comparable to DXA, it does not mitigate the need for BMD assessment and therefore a test that can simultaneously assess both in those children who do not have scoliosis/kyphosis is preferable.

The major limitations of this study (and others of diagnostic accuracy) relate to the lack of an objective gold standard. Firstly, because there is no agreed standardised objective method for the diagnosis of VF, we cannot be certain which prevalent fractures were truly fractures. We used the consensus radiographic read of three experienced observers as reference standard. Radiographic cone beam technology has the disadvantage of producing divergent $\mathrm{x}$-ray beams causing parallax and distorting the shape of the vertebrae at the extremities of the radiograph. Conversely, the fan beam technology in DXA is perpendicular to each vertebral body as the source travels down the spinal column [27]. The parallax effect seen in radiographs may affect diagnostic accuracy, particularly for subtle fractures or normal physiological change in vertebral body shape and height. It is possible that mild fractures were over-called on radiographs rather than missed on iDXA. We accept that our selected reference standard may be imperfect, but it is at least as reliable as standards used in daily practice and is expected to be reliable for those vertebral fractures that would merit treatment (height loss greater than $25 \%$ ).

Secondly, the higher intermodality agreement of individual radiograph compared to individual iDXA reads is in part to be expected, because for individual and consensus radiographs we were scoring not only the same modality but also the same images. Despite this advantage, radiographs did not significantly outperform iDXA.

Thirdly, disadvantages of consensus scoring in general are well documented [38] and applicable to this study; however, inter- and intraobserver agreement for individual reads was 
similar for both iDXA and radiographs. Therefore, for any individual radiologist, clinical opinion and hence patient management would be the same irrespective of whether diagnosis of VF was made from DXA or from radiographs.

Finally, the use of conventional statistical methods for studies of diagnostic accuracy for which there is no gold standard has been questioned and more appropriate methodology suggested [39]. An interesting future study would be to apply some of these methodologies (e.g. latent class analysis) to our raw data.

In conclusion, diagnostic accuracy of iDXA and radiographs for the detection of VF in children are comparable; parents had no strong preference for either modality, whilst the majority of children either preferred iDXA or had no preference. Incidentally we demonstrated improved image quality of iDXA for scoliosis patients with in situ spinal rods. A single iDXA scan provides an average annual effective dose reduction of at least $232.7 \mu \mathrm{Sv}$ per patient. Given the large numbers of children at risk of VF (skeletal dysplasias, steroid therapy, anticancer treatment etc.) this amounts to considerable childhood and population lifetime cumulative dose reductions. In accordance with the principles of "as low as reasonably achievable" [40] and "image gently" [41], we believe that in children with suspected reduced BMD, either with primary osteoporosis such as osteogenesis imperfecta or with secondary osteoporosis such as those treated with steroids or who have leukaemia, DXA (using modern scanners) should replace conventional radiographs for the diagnosis of VF.

Acknowledgments The views expressed are those of the authors and not necessarily those of the National Health Service (NHS), the National Institute for Health Research (NIHR) or the Department of Health.

The authors wish to thank Sheffield Children's Hospital radiographers, in particular Elzene Kruger and Julie Barnsley. The authors also express their gratitude to Nicola Crabtree, Beverly Naylor and Helen Webb.

The scientific guarantor of this publication is Dr Amaka C Offiah. ACO declares relationships with the following companies: BioMarin, InfoMed and Alexion (receipt of honoraria for lectures, advisory board work and/or on-line teaching material). BioClinica (previously interpreted spine radiographs for this company based on the Genant technique). NJB declares relationships with the following companies over the last 36 months: Alexion, Amgen, Merck (grants for clinical research); Alexion, Amgen (honoraria for speaking at meetings); Internis, Ultragenyx, Alexion (payments for advisory board work); Amgen, UCB (payment for consulting). The remaining authors of this manuscript declare no relationships with any companies whose products or services may be related to the subject matter of the article. This study has received funding from National Institute for Health Research, Research for Patient Benefit (NIHR RfPB) Reference PB-PG-0110-21240. Two of the authors (AA and SW) have significant statistical expertise. Research ethics committee (institutional review board) approval was obtained. Written informed consent was obtained from all subjects (patients) in this study.

Some study subjects or cohorts have been previously reported in "Diagnosis of vertebral fractures in children: is a simplified algorithmbased qualitative technique reliable?" by Adiotomre E, Summers L, Allison A et al. (2016) Pediatr Radiol. doi:10.1007/s00247-015-3537-z.
Methodology: prospective, cross-sectional study/diagnostic study, performed at two institutions.

Open Access This article is distributed under the terms of the Creative Commons Attribution 4.0 International License (http:// creativecommons.org/licenses/by/4.0/), which permits unrestricted use, distribution, and reproduction in any medium, provided you give appropriate credit to the original author(s) and the source, provide a link to the Creative Commons license, and indicate if changes were made.

\section{References}

1. Rajaraman P, Simpson J, Neta G et al (2011) Early life exposure to diagnostic radiation and ultrasound scans and risk of childhood cancer: case-control study. Br Med J 342:d472

2. Blake GM, Naeem M, Boutros M (2006) Comparison of effective dose to children and adults from dual X-ray absorptiometry examinations. Bone 38:935-942

3. Mathews JD, Forsythe AV, Brady Z et al (2013) Cancer risk in 680, 000 people exposed to computed tomography scans in childhood or adolescence: data linkage study of 11 million Australians. Br Med J 346:f2360

4. Bajaj M, Offiah AC (2015) Imaging in suspected child abuse: necessity or radiation hazard? Arch Dis Child 100:1163-1168

5. Wall BF, Haylock R, Jansen JTM, Hillier MC, Hart D, Shrimpton PC (2011) Radiation risks from medical x-ray examinations as a function of the age and sex of the patient. Health Protection Agency. Centre for Radiation, Chemical land Environmental Hazards. HPA-CRCE-028 https://www.gov.uk/government/uploads/system/uploads/attachment data/file/340147/HPA-CRCE-028_for_website.pdf. Accessed $2 \overline{3}$ Jan 2016

6. Ozasa K, Shimizu Y, Suyama A et al (2012) Studies of the mortality of atomic bomb survivors, Report 14, 1950-2003: an overview of cancer and noncancer diseases. Radiat Res 177:229-243

7. Ronckers CM, Doody MM, Lonstein JE, Stovall M, Land CE (2008) Multiple diagnostic X-rays for spine deformities and risk of breast cancer. Cancer Epidemiol Biomarkers Prev 17:605-613

8. Boice JD Jr, Preston D, Davis FG, Monson RR (1991) Frequent chest X-ray fluoroscopy and breast cancer incidence among tuberculosis patients in Massachusetts. Radiat Res 125:214-222

9. US National Academy of Sciences. National Research Council. Committee to Assess Health Risks from Exposure to Low Levels of Ionizing Radiation Health Risks from Exposure to Low Levels of Ionizing Radiation. BEIR VII Phase 2. Washington DC: National Academies Press, 2006. http://dels.nas.edu/resources/staticassets/materials-based-on-reports/reports-in-brief/beir_vii_final. pdf. Accessed 23 Jan 2016

10. Van Aalst J, Jeukens CR, Vles JS et al (2013) Diagnostic radiation exposure in children with spinal dysraphism: an estimation of the cumulative effective dose in a cohort of 135 children from the Netherlands. Arch Dis Child 98:680-685

11. Genant HK, Li J, Wu CY, Shepherd JA (2000) Vertebral fractures in osteoporosis: a new method for clinical assessment. J Clin Densitom 3:281-290

12. Lewiecki EM, Laster AJ (2006) Clinical review: clinical applications of vertebral fracture assessment by dual-energy x-ray absorptiometry. J Clin Endocrinol Metab 91:4215-4222

13. Buehring B, Krueger D, Checovich M et al (2010) Vertebral fracture assessment: impact of instrument and reader. Osteoporos Int 21:487-494

14. Hospers IC, van der Laan JG, Zeebregts CJ et al (2009) Vertebral fracture assessment in supine position: comparison by using 
conventional semiquantitative radiography and visual radiography. Radiology 251:822-828

15. Schousboe JT, Debold CR (2006) Reliability and accuracy of vertebral fracture assessment with densitometry compared to radiography in clinical practice. Osteoporos Int 17:281-289

16. Binkley N, Krueger D, Gangnon R, Genant HK, Drezner MK (2005) Lateral vertebral assessment: a valuable technique to detect clinically significant vertebral fractures. Osteoporos Int 16:1513-1518

17. Rea JA, Chen MB, Li J et al (2000) Morphometric X-ray absorptiometry and morphometric radiography of the spine: a comparison of prevalent vertebral deformity identification. J Bone Miner Res 15:564-574

18. Ferrar L, Jiang G, Eastell R, Peel NF (2003) Visual identification of vertebral fractures in osteoporosis using morphometric X-ray absorptiometry. J Bone Miner Res 18:933-938

19. Vokes TJ, Dixon LB, Favus MJ (2003) Clinical utility of dualenergy vertebral assessment (DVA). Osteoporos Int 14:871-878

20. Pavlov L, Gamble GD, Reid IR (2005) Comparison of dual-energy $\mathrm{X}$-ray absorptiometry and conventional radiography for the detection of vertebral fractures. J Clin Densitom 8:379-385

21. Fuerst T, Wu C, Genant HK et al (2009) Evaluation of vertebral fracture assessment by dual X-ray absorptiometry in a multicenter setting. Osteoporos Int 20:1199-1205

22. Diacinti D, Del Fiacco R, Pisani D et al (2012) Diagnostic performance of vertebral fracture assessment by the lunar iDXA scanner compared to conventional radiography. Calcif Tissue Int 91:335-342

23. Jager PL, Jonkman S, Koolhaas W, Stiekema A, Wolffenbuttel BH, Slart RH (2011) Combined vertebral fracture assessment and bone mineral density measurement: a new standard in the diagnosis of osteoporosis in academic populations. Osteoporos Int 22:1059-1068

24. Damiano J, Kolta S, Porcher R, Tournoux C, Dougados M, Roux C (2006) Diagnosis of vertebral fractures by vertebral fracture assessment. J Clin Densitom 9:66-71

25. Schousboe JT, Shepherd JA, Bilezikian JP, Baim S (2013) Executive summary of the 2013 ISCD position development conference on bone densitometry. J Clin Densitom 16:455-467

26. Bishop N, Arundel P, Clark E et al (2014) Fracture prediction and the definition of osteoporosis in children and adolescents: the ISCD 2013 pediatric official positions. J Clin Densitom 17: $275-280$

27. Mäyränpää MK, Helenius I, Valta H, Mäyränpää MI, ToiviainenSalo S, Mäkitie O (2007) Bone densitometry in the diagnosis of vertebral fractures in children: accuracy of vertebral fracture assessment. Bone 41:353-359
28. Vokes T, Bachman D, Baim S (2006) Vertebral fracture assessment: the 2005 ISCD Official Positions. J Clin Densitom 9:37-46

29. Lentle BS, Brown JP, Khan A et al (2007) Recognizing and reporting vertebral fractures: reducing the risk of future osteoporotic fractures. Can Assoc Radiol J 58:27-36

30. European guidelines on quality criteria for diagnostic radiographic images in paediatrics. EUR 16261 Luxembourg: European Commission 1996. ftp://ftp.cordis.europa.eu/pub/fp5euratom/docs/eur16261.pdf. Accessed 23 Jan 2016

31. Adiotomre E, Summers L, Allison A et al (2016) Diagnosis of vertebral fractures in children: is a simplified algorithmbased qualitative technique reliable? Pediatr Radiol. doi:10.1007/s00247-015-3537-z

32. Diacinti D, Pisani D, D'Avanzo M et al (2015) Reliability of vertebral fractures assessment (VFA) in children with osteogenesis imperfecta. Calcif Tissue Int 96:307-312

33. Kyriakou A, Shepherd S, Mason A, Faisal Ahmed S (2015) A critical appraisal of vertebral fracture assessment in paediatrics. Bone 81:255-259

34. Siminoski K, Lentle B, Matzinger A, Shenouda N, Ward L (2014) The Canadian STOPP Consortium. Observer agreement in pediatric semiquantitative vertebral fracture diagnosis. Pediatr Radiol 44:457-466

35. Melhem E, Assi A, El Rachkidi R, Ghanem I (2016) EOS(®) biplanar X-ray imaging: concept, developments, benefits, and limitations. J Child Orthop 10:1-14

36. McKenna $\mathrm{C}$ et al (2012) EOS 2D/3D X-ray imaging system: a systematic review and economic evaluation. Health Technol Assess 16:1-188

37. NICE diagnostics guidance [DG1]. The EOS 2D/3D imaging system. October 2011. https://www.nice.org.uk/guidance/dg1 /resources/the-eos-2d3d-imaging-system-29267263429. Accessed 03 July 2016

38. Bankler AA, Levine D, Halpem EF, Kressel HY (2010) Consensus interpretation in imaging research: Is there a better way? Radiology 257:14-17

39. Rutjes AWA, Reitsma JB, Coomarsamy A, Khan KS, Bossuyt PM (2007) Evaluation of diagnostic tests when there is no gold standard. A review of methods. Health Technol Assess 11:9-51

40. Ionising Radiation (Medical Exposure) Regulations 2000 (IRMER). Department of Health. September 2012 www.gov. uk/government/uploads/system/uploads/attachment data/file/227075/IRMER regulations 2000.pdf. Accessed $2 \overline{3}$ Jan 2016

41. The Alliance for Radiation Safety in Pediatric Imaging, Image Gently http://www.imagegently.org. Accessed 15 Mar 2016 